\title{
KONTROL KECEPATAN MOTOR INDUKSI TIGA FASA MENGGUNAKAN TEGANGAN DAN FREKUENSI DENGAN MODULASI VEKTOR RUANG
}

\author{
Dwi Sasmita Aji Pambudi ${ }^{1}$, M. Sarwoko², Ekki Kurniawan ${ }^{3}$ \\ 1,2,3 Fakultas Teknik Elektro, Universitas Telkom
}

1'dwi.sasmita@hotmail.com, ${ }^{2}$ swkknk@telkomuniversity.ac.id, ${ }^{3}$ ekkikurniawan@telkomuniversity.ac.id

\begin{abstract}
Abstrak
Teknik pengontrolan motor induksi tiga fasa yang digunakan pada penelitian ini adalah kontrol tegangan dan frekuensi (Volt/Hertz). Metode kontrol tersebut, mampu menjaga besarnya fluks dan nilai torsi maksimum agar tetap konstan. Metode Modulasi Ruang Vektor (Space Vector Modulation) ditanamkan pada mikrokontroler STM32F100 untuk pembangkitan pulsa PWM inverter sesuai dengan urutan pensakelaran inverter tiga fasa sumber tegangan (VSI). Lebar pulsa dari tiap pulsa PWM ditentukan oleh pengaturan variabel waktu dalam SVM. Kontrol sistem dilakukan secara loop terbuka dengan mengubahubah nilai set point kecepatan yaitu mengatur nilai frekuensi yang secara bersamaan mengatur nilai tegangan sesuai nilai indeks modulasi. Penggunaan kontrol skalar (Volt/Hertz) mampu menahan lonjakan arus mula motor saat motor mulai dijalankan secara langsung, yaitu besarnya arus mula motor sebesar 3,12 A dapat ditekan menjadi $\approx 2,9 \mathrm{~A}$. Nilai rata-rata error pengukuran pada pengujian kecepatan motor sesuai dengan nilai faktor slip yaitu sebesar $6 \%$. Nilai kecepatan motor yang dihasilkan memiliki hubungan linier dengan nilai frekuensi yang diberikan. Semakin kecil nilai tegangan keluaran inverter, maka semakin besar nilai THD dan semakin besar harmonisa yang dihasilkan oleh motor yang menyebabkan motor tidak dapat bekerja secara optimal. Implementasi dari sistem kontrol memberikan rata-rata nilai error 1,935\% .
\end{abstract}

Kata Kunci: motor induksi, Volt/Hertz, STM32F100, inverter, SVM

\section{Abstract}

Control method of three-phase induction motor, which is used in this paper, is control of voltage and frequency (Volts/Hertz). The control method is able to maintain the amount of flux and maximum torque to remain constant. Space Vector Modulation is implemented on STM32F100 microcontroller to generate PWM inverter in accordance with the switching sequence of the three-phase voltage source inverter (VSI). Pulse width of each PWM is determined by setting a time variable in SVM. Control system is performed with open-loop system by varying the set point of speed, set the frequency and the voltage value appropriate with the modulation index. Scalar control (Volt/Hertz) is able to withstand inrush current when the motor first running directly and the motor initial current of $3.12 \mathrm{~A}$ can be reduced to $\approx 2.9 \mathrm{~A}$. The average value of the measurement error in testing the motor speed according to the slip factor is equal to $6 \%$. The motor speed is linear with a given frequency. The smaller the inverter output voltage, the greater the THD value and the greater the harmonics generated by the motor, causes the motor unable to work optimally. Implementation of control system gives an average error value of $1.935 \%$.

Keywords: induction motor, Volt/Hertz, STM32F100, inverter, SVM

\section{Pendahuluan}

Motor induksi banyak diaplikasikan di berbagai sektor mulai dari rumah tangga sampai industri. Motor induksi banyak digunakan karena karakteristiknya yang kokoh, handal, dan biaya perawatannya murah. Di sisi lain, motor induksi juga memiliki kekurangan yaitu sulit untuk dikontrol dan memiliki arus mula yang biasanya enam kali dari arus nominalnya.

Salah satu bentuk aplikasi motor induksi dalam industri adalah penggunaan pada conveyor untuk pengangkutan batu bara di Pembangkit Listrik
Tenaga Uap. Pengontrolan motor tersebut diharapkan dapat mempermudah operator untuk mengatur kecepatan motor dengan mengubah nilai parameter tertentu pada tampilan grafis komputer.

Teknik pengontrolan motor induksi dapat dilakukan dengan metode kontrol sakelar. Kontrol skalar dilakukan dengan linierisasi model persamaan non linier motor induksi saat beroperasi pada keadaan mantap (steady state), yaitu dengan menjaga perbandingan antara besarnya tegangan stator (magnitude) terhadap frekuensi $(\omega)$ agar selalu bernilai konstan [2] sehingga nilai fluks dan torsi maksimum selalu konstan. 
Pengaturan nilai parameter masukan kontrol skalar, yaitu nilai frekuensi dan tegangan keluaran, dilakukan di dalam inverter. Pengaturan tersebut dilakukan dengan mengatur nilai tegangan masukan inverter yang konstan dan mengatur lebar pulsa untuk buka tutup gerbang tiap transistor IGBT dalam inverter.

Pembangkitan pulsa PWM dilakukan dengan menggunakan algoritma Space Vector Modulation (SVM). Penggunaan algoritma tersebut memungkinkan untuk mengatur nilai frekuensi dan nilai amplitudo tegangan referensi. Algoritma SVM mampu mengurangi harmonik sinyal keluaran yang tidak dapat dilakukan oleh filter.

Pada penelitian ini, digunakan motor induksi tiga fasa yang dioperasikan dengan inverter sumber catuan satu fasa, sehingga lebih fleksibel dan praktis untuk digunakan dimanapun.

\section{Landasan Teori}

\subsection{Kontrol Tegangan Stator dan Frekuensi}

Jika perbandingan tegangan terhadap frekuensi dijaga agar tetap konstan, fluks juga akan tetap konstan. Besarnya torsi maksimum yang tidak bergantung pada nilai frekuensi, dapat diatur agar konstan. Akan tetapi, pada frekuensi tinggi, fluks celah udara berkurang menjadi rendah pada impedansi stator dan tegangan menjadi meningkat untuk mengatur level torsinya [3]. Kontrol tegangan dan frekuensi tersebut juga disebut sebagai kontrol Volt/Hertz. Jika $\omega_{s}=\beta \omega_{b}$ dan perbandingan tegangan terhadap frekuensi konstan, maka:

$$
\frac{V_{a}}{\omega_{s}}=d
$$

dengan rasio $d$ dapat didefinisikan dari tegangan $V_{s}$ dan kecepatan dasar $\omega_{b}$, sebagai:

$$
d=\frac{V_{s}}{\omega_{b}}
$$

melalui proses substitusi nilai dari persamaan (1) ke dalam nilai torsi:

$$
T_{d}=\frac{3 R_{r}^{\prime} V_{a}^{2}}{s \beta \omega_{b}\left[\left(R_{s}+\frac{R_{r}^{\prime}}{s}\right)^{2}+\left(\beta X_{s}+\beta X_{s}^{\prime}\right)^{2}\right]^{\prime}}
$$

maka, nilai slip untuk torsi maksimum adalah:

$$
s_{m}=\frac{R_{r}^{\prime}}{\left[R_{s}^{2}+\beta^{2}\left(X_{s}+X_{r}^{\prime}\right)^{2}\right]^{\frac{1}{2}}}
$$

Jika frekuensi dikurangi, maka $\beta$ berkurang dan slip untuk torsi maksimum meningkat. Untuk torsi beban yang diberikan, kontrol kecepatan dapat dilakukan berdasarkan persamaan (2) dengan mengubah frekuensinya. Sehingga dengan mengubah-ubah nilai tegangan dan frekuensi, torsi dan kecepatan dapat dikontrol. Torsi dapat diatur konstan untuk kecepatan berubah-ubah. Tegangan pada nilai frekuensi variabel dapat diperoleh pada inverter tiga fasa atau cycloconverter [3]. Bentuk kurva karakteristik torsi-kecepatan ditunjukkan pada Gambar 1.

\subsection{Modulasi Vektor Ruang}

Modulasi Ruang vektor atau Space Vector Modulation (SVM) digunakan untuk mengontrol tegangan keluaran quasi/square pada inverter tiga fasa berdasarkan enam kombinasi kemungkinan keadaan yang menghasilkan enam vektor tegangan aktif dan dua vektor tegangan nol yang mempresentasikan tegangan keluaran space vector. Dalam pencatuan tegangan DC, modulasi ruang vektor menghasilkan efisiensi yang lebih baik dibandingkan dengan teknik modulasi lainnya [3]. Nilai space vector ditunjukkan pada Gambar 2. Seperti pada Gambar 3, pada modulasi ruang vektor, terdapat enam sektor yaitu $V_{1}(100), V_{2}(110), V_{3}(010)$, $V_{4}(011), V_{5}(001), V_{6}(101)$, serta dua buah vektor nol $V_{7}(111)$ dan $V_{0}(000)$.

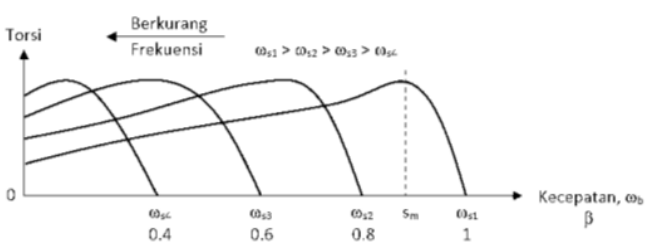

Gambar 1. Karakteristik Torsi-Kecepatan dengan Kontrol Volt/Hertz

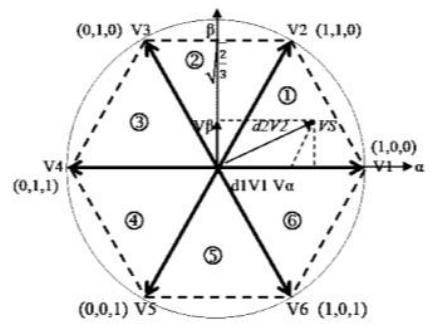

Gambar 2. Nilai dari Space Vector

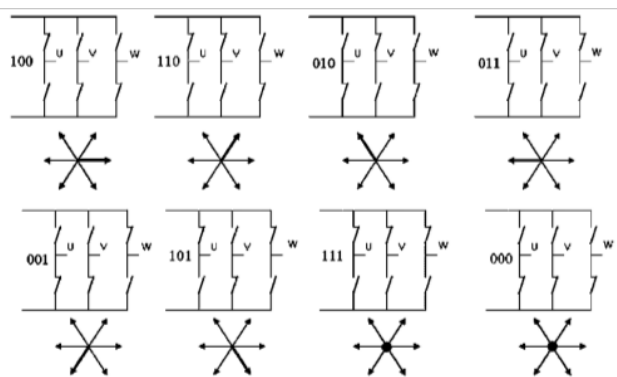

Gambar 3. Kemungkinan Pensakelaran pada Inverter Tiga Fasa 
Untuk mengurangi harmonik pada sinyal keluaran, maka urutan ruang keadaan harus menghasilkan quarter-wave yang simetris pada tegangan beban keluaran. Selain itu, untuk mengurangi frekuensi pensakelaran, yaitu banyaknya pensakelaran dalam satu siklus, maka dalam urutannya, pensakelaran hanya terjadi pada satu pasangan transistor saja dalam satu transisi dari satu keadaan ke keadaan lainya. Sehingga urutan pensakelaran yang memungkinkan adalah $V_{z}, V_{n}$, $V_{n+1}$, dan $V_{z}$. Dengan $V_{z}$ adalah pilihan alternatif antara $V_{0}$ dan $V_{7}$ [3].

Parameter-parameter yang diperlukan untuk menghasilkan keluaran inverter sinyal PWM adalah $T_{a}, T_{b}, T_{0}$. Vektor referensi dapat dinyatakan dalam dua buah vektor $V_{1}, V_{2}$, dan vektor nol $\left(V_{0}\right.$ atau $\left.V_{7}\right)$ dalam artian $V_{1}$ aktif dalam waktu $T_{1}$ dan $V_{2}$ aktif dalam waktu $T_{2}$ dan $V_{0}$ atau $V_{7}$ aktif dalam waktu $T_{z}$. Dalam frekuensi pensakelaran yang tinggi, vektor referensi $V_{r}$ dapat diasumsikan konstan selama satu periode pensakelaran [3]. Karena $V_{1}$ dan $V_{2}$ konstan serta $V_{z}=0$, maka vektor referensi dalam ruang keadaan dapat dituliskan sebagai:

$$
V_{r} \times T_{s}=V_{1} \times T_{1}+V_{2} \times T_{2}+V_{z} \times T_{z}
$$

Vektor diagram dari persamaan tersebut disajikan pada Gambar 4.

Jika persamaan (4) dinyatakan dalam koordinat ruang keadaan (Gambar 2), maka:

$$
\begin{aligned}
T_{s} V_{r e f}\left(\begin{array}{c}
\cos \theta \\
\sin \theta
\end{array}\right)= & T_{1}\left(\frac{2}{3} V_{d c}\right)\left(\begin{array}{c}
\cos 0 \\
\sin 0
\end{array}\right)+ \\
& T_{2}\left(\frac{2}{3} V_{d c}\right)\left(\begin{array}{c}
\cos \frac{\pi}{3} \\
\sin \frac{\pi}{3}
\end{array}\right)+T_{z} 0
\end{aligned}
$$

dengan nilai $0 \leq \theta \leq \pi / 3$. Sehingga didapatkan hasil $T_{1}, T_{2}$, dan $T_{0}$, yaitu:

$$
\begin{gathered}
T_{1}=T_{s} M\left(\sin \frac{n \pi}{3}-\theta\right) \\
T_{2}=T_{s} M\left(\sin \left(\theta-\frac{(n-1) \pi}{3}\right)\right) \\
T_{0}=T_{s}-T_{1}-T_{2}
\end{gathered}
$$

dengan:

$$
\begin{aligned}
& T_{s}=\frac{1}{f_{s}} ; \quad M=\frac{\sqrt{3} V_{\text {fasa-fasa }}}{V_{d c}}=\frac{V_{\text {ref }}}{V_{d c}} ; \\
& \theta=\frac{2 \pi a_{m}}{m} ; \quad 1 \leq n \leq 6
\end{aligned}
$$

di mana $f_{s}$ adalah frekuensi pencuplikan (sampling), $\theta$ adalah sudut antara $V_{r}$ dan $V_{n}, m$ adalah jumlah sampling, $a_{m}$ adalah nomor sampling, $n$ adalah nomor sektor, dan $M$ adalah nilai indeks modulasi, $0 \leq M \leq$ 1.

\section{Perancangan dan Implementasi Sistem}

\subsection{Perancangan Perangkat Keras}

Pada piranti keras terdapat tiga blok yang membentuk sistem kontrol. Blok pertama merupakan blok kontroler yang terdapat dalam mikrokontroler STM32F100 pada STM32 Value Line Discovery [8]. Sedangkan blok kedua merupakan blok inverter dengan sinyal masukan PWM. Blok ketiga merupakan blok sensor untuk mengukur besarnya tegangan sumber $V s$, suhu heatsink dari inverter dan kecepatan putaran motor induksi. Blok diagram dari sistem kontrol motor induksi ditunjukkan pada Gambar 5.

Blok kontroler memiliki fungsi sebagai pusat pengendalian dari keseluruhan sistem, baik untuk pembangkitan sinyal PWM, pembacaan data sensor, maupun komunikasi serial dengan komputer untuk kontrol sistem atau pengamatan data.

Pada blok inverter tiga fasa, digunakan board STEVAL-IHM027V1 [9] yang dapat mengontrol motor AC tiga fasa $1 \mathrm{~kW}$. STEVAL-IHM027V1 terdiri dari blok catu daya (rectifier), blok kontrol sebagai pin masukan, dan blok daya inverter. Blokblok tersebut terhubung dengan konektor yang terdapat pada board yang berfungsi sebagai masukan atau keluaran sistem.

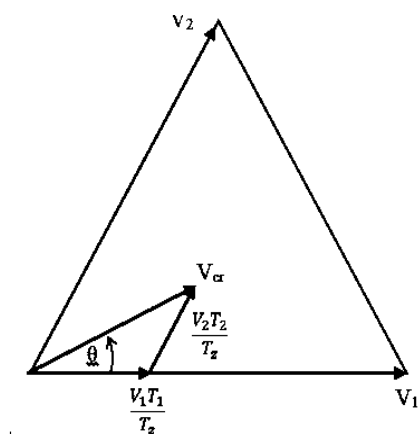

Gambar 4. Penetuan Waktu Keadaan

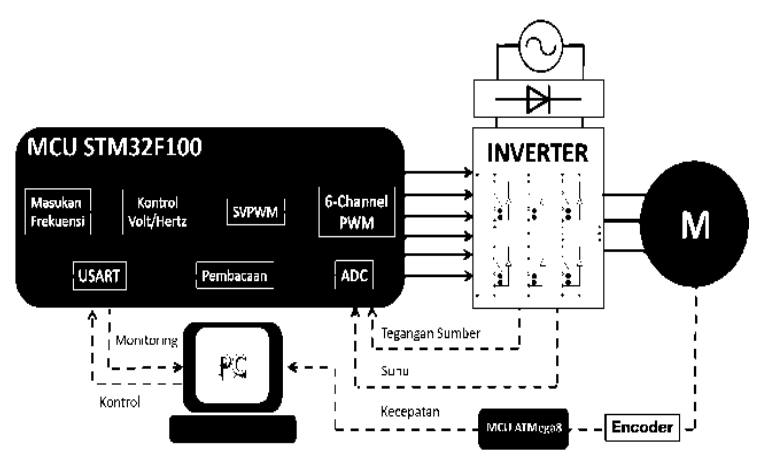

Gambar 5. Blok Diagram Sistem Kontrol Motor Induksi Tiga Fasa 
Pada blok sensor terdapat rangkaian pengkondisi sinyal untuk pengukuran besarnya tegangan bus suhu heatsink inverter, dan pengolahan data sensor untuk pengukuran kecepatan menggunakan encoder. Pengukuran kecepatan dilakukan dengan menggunakan sensor Rotary Encoder Autonics E40S6-360-3-T-24. Penghitungan kecepatan dilakukan di dalam mikrokontroler ATMega8. Hasil perhitungan tersebut, dikirimkan langsung ke komputer untuk ditampilkan pada GUI. Pemasangan sensor encoder dilakukan dengan cara mengkopel shaft encoder dengan shaft motor. Sehingga saat motor berputar, maka encoder juga ikut berputar.

\subsection{Perancangan Perangkat Lunak}

\subsubsection{Perancangan Sistem Kontroler}

Kontrol kecepatan motor induksi dilakukan secara loop terbuka dengan nilai set point kecepatan yang menjadi nilai referensi kecepatan putaran pada motor. Diagram blok dari sistem kontrol kecepatan pada motor induksi tiga fasa tersebut ditunjukkan pada Gambar 8

\subsubsection{Perancangan Kontrol Skalar dan SVM}

Besarnya nilai kecepatan motor ditentukan oleh nilai tegangan dan nilai frekuensi yang dicatu ke motor berdasarkan kontrol skalar (Volt/Hertz). Penentuan nilai tegangan didasarkan pada nilai rasio tegangan terhadap frekuensi sesuai persamaan (2). Nilai tegangan motor adalah $220 \mathrm{~V}$ dan nilai frekuensi motor adalah $50 \mathrm{~Hz}$. Sedangkan nilai kecepatan dasarnya $\omega_{b}$ didapatkan dari persamaan (2):

$$
\begin{aligned}
\omega_{b} & =\omega_{s}=\frac{2 \omega}{p}=\frac{2(2 \pi f)}{p} \\
& =\frac{2(2 \cdot \pi \cdot 50)}{2}=100 \pi
\end{aligned}
$$

Sehingga besarnya nilai rasio $d$ adalah:

$$
d=\frac{V_{s}}{\omega_{b}}=\frac{220}{100 \pi} \approx 0,7
$$

Besarnya nilai tegangan keluaran inverter ditentukan berdasarkan dari persamaan (1), yaitu:

$$
V_{a}=d \omega_{s}=\frac{220}{100 \pi} \frac{2(2 \pi f)}{2}=\frac{220 f}{50}
$$

Nilai tegangan keluaran inverter yang didapatkan kemudian dimasukkan ke dalam variabel nilai indeks modulasi untuk menentukan pembangkitan sinyal PWM pada inverter.
Berdasarkan nilai tegangan tersebut, maka nilai indeks modulasi menjadi:

$$
M=\frac{V_{a}}{V_{s}}=\frac{220 f / 50}{220}=\frac{f}{50}
$$

Masukan nilai kecepatan kemudian diubah ke dalam bentuk nilai frekuensi dan indeks modulasi melalui suatu persamaan. Persamaan tersebut didapatkan dari grafik perbandingan nilai frekuensi dan indeks modulasi terhadap kecepatan. Diagram alir dari kontrol skalar ditunjukkan oleh Gambar 9.

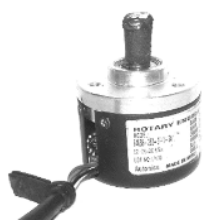

Gambar 6. Rotary Encoder Autonics E40S6-360-3-T-24

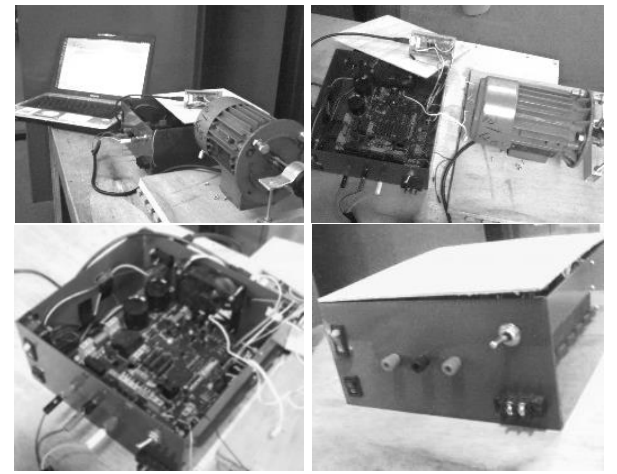

Gambar 7. Implementasi Perangkat Keras

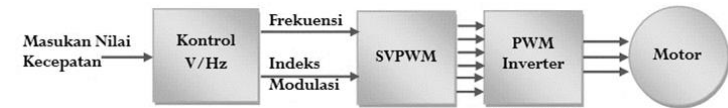

Gambar 8. Diagram Blok Kontrol Volt/Hertz

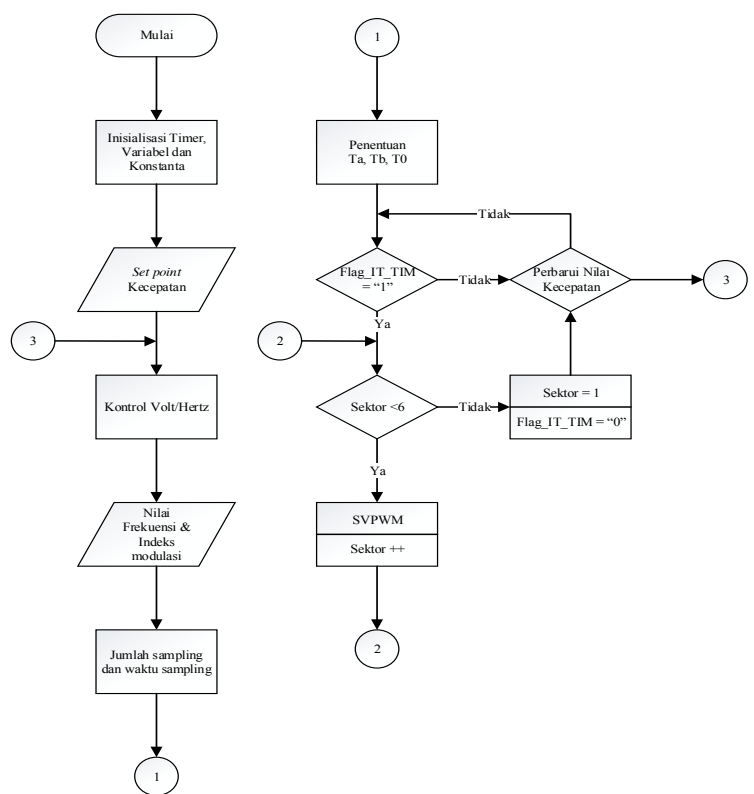

Gambar 9. Diagram Alir Program Utama 


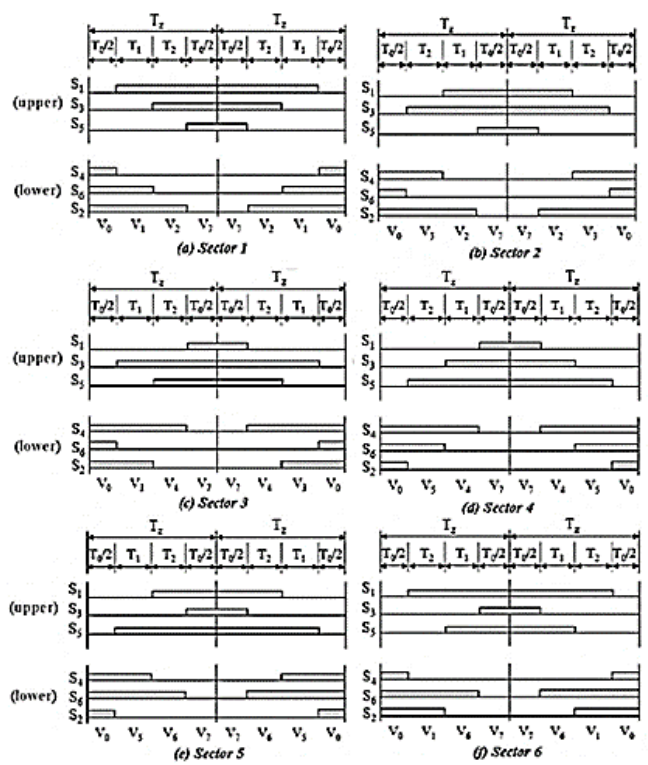

Gambar 10. Pola Pensakelaran SVM [4]

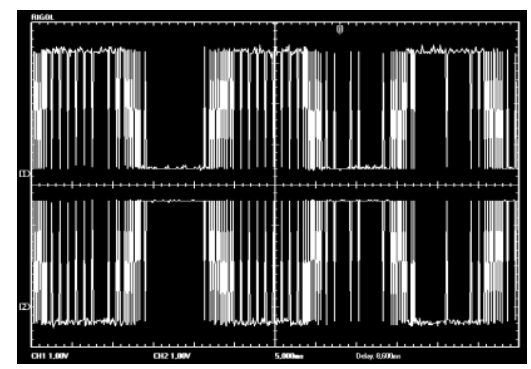

(a)

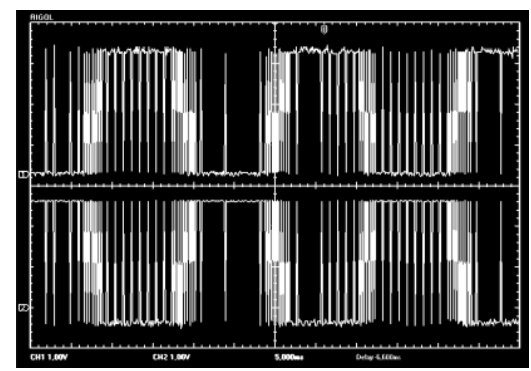

(b)

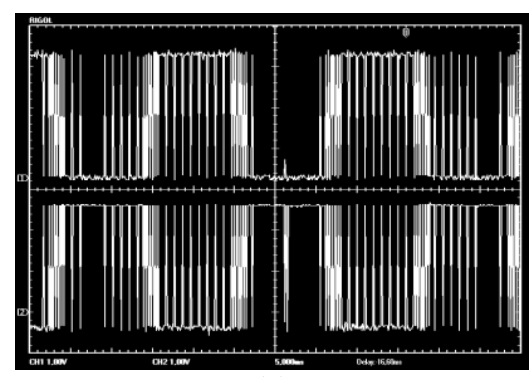

(c)

Gambar 11. Sinyal PWM High dan Low Tiap Fasa pada Frekuensi 50 Hz: (a) untuk Fasa A, (b) untuk Fasa B, dan (c) untuk Fasa C

Sinyal pulsa PWM untuk sakelar high dan low saling berpasangan dan berkebalikan (inverted) yang diatur mengaktifkan Output State dan Output N State pada program. Selain itu, diperlukan waktu jeda (dead time) untuk pembangkitan pulsa high dan low agar transistor high dan low bekerja secara bergantian dan menghindari adanya hubungan singkat. Pola pensakelaran dan pembangkitan pulsa PWM pada tiap sektor [4] ditunjukkan oleh Gambar 10.

Pola pensakelaran dapat dilakukan dengan menggabungkan pola waktu ON dan waktu OFF dari pensakelaran tiap sektor. Pola waktu ON dan OFF tersebut dihasilkan dengan membangkitkan pulsa PWM berdasarkan siklus kerja (duty cycle). Penentuan periode pulsa PWM dan besarnya siklus kerja didasarkan pada nilai $T_{1}, T_{2}$, dan $T_{0}$ sesuai dengan persamaan (6), (7), dan (8). Nilai $T_{1}, T_{2}$, dan $T_{0}$ tersebut bergantung pada nilai frekuensi dan nilai indeks modulasi yang diberikan.

Pada sistem yang dirancang, digunakan frekuensi sampling $6000 \mathrm{~Hz}$ dan waktu sampling $\left(T_{s}\right)$ adalah $166,67 \mu \mathrm{s}$. Waktu sampling $\left(T_{s}\right)$ pada pola pensakelaran merupakan penjumlahan dari $T_{1}, T_{2}$, dan $T_{0}$, sehingga besarnya lebar periode PWM adalah dua kali waktu sampling $\left(T_{s}\right)$.

$$
\begin{aligned}
T_{P W M}=2 T_{s} & =2(166,67) \\
& =333,33 \mu \mathrm{s}
\end{aligned}
$$

Sedangkan jumlah $333,33 \mu$ s sampling ditentukan berdasarkan besarnya periode dari nilai frekuensi masukan $\left(T_{i n}\right)$ dan nilai periode PWM $\left(T_{P W M}\right)$ yang dituliskan menjadi:

$$
\sum \text { sampling }=\frac{T_{i n}}{T_{P W M}}=\frac{1 / f_{i n}}{333 \mu \mathrm{s}}=\frac{10^{6}}{333 f_{i n}}
$$

Jumlah sampling menentukan jumlah terjadinya interupsi Timer 1 . Untuk $f_{\text {in }}=50 \mathrm{~Hz}$, maka:

$$
\sum \text { sampling }=\frac{10^{6}}{333 f_{\text {in }}}=\frac{10^{6}}{333 \cdot 50}=60 \text { sampling }
$$

yang dibagi ke dalam 6 sektor. Sehingga jumlah sampling tiap sektor adalah 10 buah sampling.

Berdasarkan nilai variabel yang telah diketahui sebelumnya, maka untuk mendapatkan nilai $\mathrm{T}_{1}, \mathrm{~T}_{2}$, dan $\mathrm{T}_{0}$, digunakan algoritma perhitungan berikut ini:

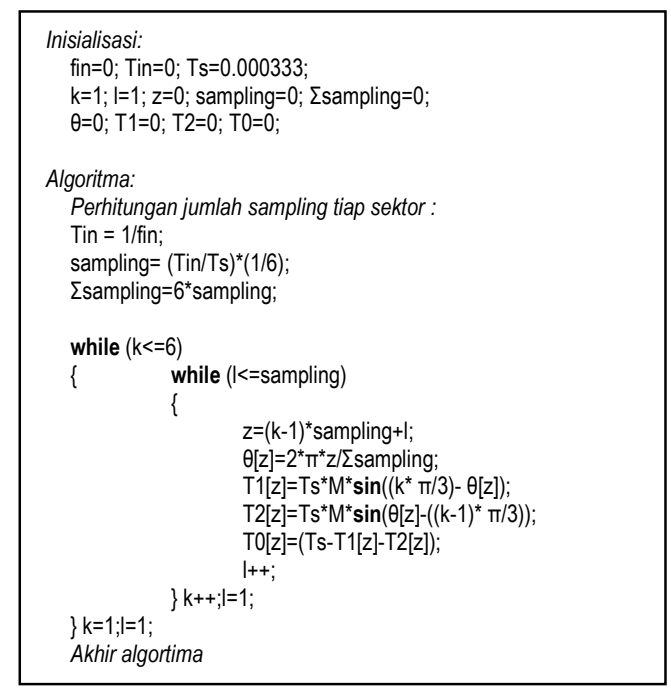


Tabel 1. Nilai Tegangan Keluaran Fasa ke Fasa

\begin{tabular}{|c|c|c|c|c|c|}
\hline \multirow{2}{*}{$\begin{array}{c}\text { Frekuensi } \\
(\mathrm{Hz})\end{array}$} & \multirow{2}{*}{$\begin{array}{c}\text { Indeks } \\
\text { Modulasi }\end{array}$} & \multicolumn{3}{|c|}{ Tegangan Fasa-Fasa (Vac) } & \multirow{2}{*}{$\begin{array}{l}V_{\mathrm{F}-\mathrm{F}} \\
(\mathrm{Vac})\end{array}$} \\
\hline & & $A-B$ & B-C & A-C & \\
\hline 10 & 0,2 & 59,02 & 58,20 & 58,71 & 58,64 \\
\hline 15 & 0,3 & 84,9 & 84,6 & 84,7 & 84,73 \\
\hline 20 & 0,4 & 107,1 & 106,9 & 107,4 & 107,13 \\
\hline 25 & 0,5 & 127,1 & 126,2 & 126,3 & 126,53 \\
\hline 30 & 0,6 & 145,1 & 143,7 & 144,4 & 144,40 \\
\hline 35 & 0,7 & 160,3 & 159,3 & 160,4 & 160 \\
\hline 40 & 0,8 & 176,0 & 174,6 & 175,2 & 175,27 \\
\hline 45 & 0,9 & 190,2 & 188,5 & 189 & 189,23 \\
\hline 50 & 1 & 205,4 & 203,2 & 204,2 & 204,27 \\
\hline
\end{tabular}

Tabel 2. Nilai Arus Keluaran Tiap Fasa pada Kontrol Skalar

\begin{tabular}{|c|c|c|c|c|c|}
\hline \multirow{2}{*}{$\begin{array}{c}\text { Frekuensi } \\
(\mathbf{H z})\end{array}$} & Indeks & \multicolumn{3}{|c|}{ Arus Tiap Fasa (A) } & \multirow{2}{*}{ I $_{\mathbf{F}}(\mathbf{A})$} \\
\hline & Modulasi & $\mathbf{A}$ & $\mathbf{B}$ & $\mathbf{C}$ & \\
\hline $\mathbf{1 0}$ & 0,2 & 2,874 & 2,868 & 2,888 & 2,877 \\
\hline $\mathbf{1 5}$ & 0,3 & 2,897 & 2,905 & 2,905 & 2,902 \\
\hline $\mathbf{2 0}$ & 0,4 & 2,898 & 2,911 & 2,909 & 2,906 \\
\hline $\mathbf{2 5}$ & 0,5 & 2,903 & 2,914 & 2,912 & 2,910 \\
\hline $\mathbf{3 0}$ & 0,6 & 2,900 & 2,917 & 2,914 & 2,910 \\
\hline $\mathbf{3 5}$ & 0,7 & 2,897 & 2,918 & 2,915 & 2,910 \\
\hline $\mathbf{4 0}$ & 0,8 & 2,895 & 2,921 & 2,918 & 2,912 \\
\hline $\mathbf{4 5}$ & 0,9 & 2,895 & 2,927 & 2,923 & 2,915 \\
\hline $\mathbf{5 0}$ & 1 & 2,895 & 2,933 & 2,927 & 2,919 \\
\hline
\end{tabular}

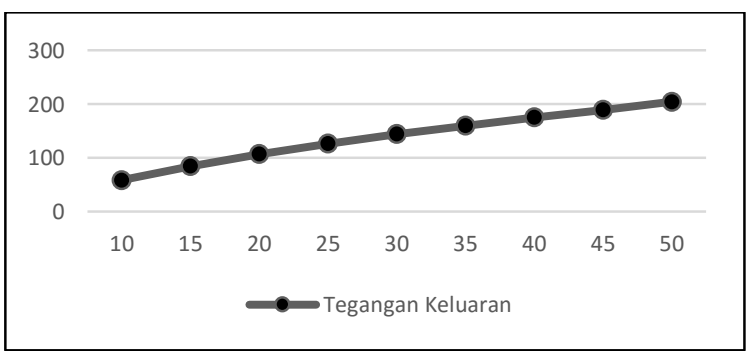

Gambar 12. Tegangan Keluaran - Frekuensi

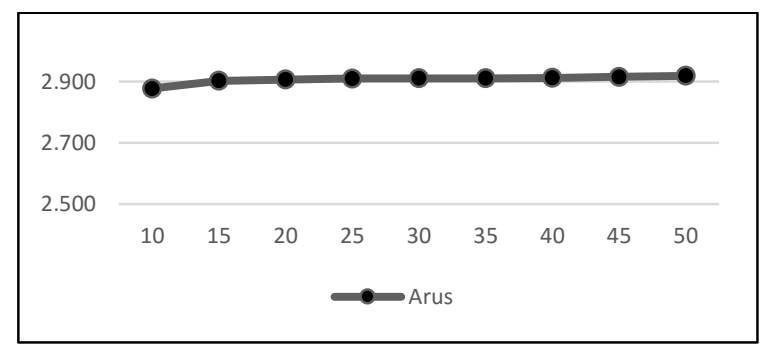

Gambar 13. Arus Fasa Terhadap Frekuensi

\section{Pengujian Sistem dan Analisis}

Pengujian dilakukan untuk mengetahui bentuk sinyal keluaran PWM dari mikrokontroler dengan implementasi modulasi ruang vektor yang menjadi sinyal masukan pada inverter. Terdapat dua buah sinyal hasil keluaran PWM yang saling berkebalikan (inverted) yang mengatur gerbang transistor high dan transistor low. Kedua pasangan sinyal keluaran PWM untuk fasa A, B, dan C, ditunjukkan oleh Gambar 11. Sedangkan hasil pengukuran tegangan keluaran antar fasa ke fasa dan nilai arus pada tiap fasa ditunjukkan pada Tabel 1 dan 2.

Pada motor tiga fasa dengan susunan delta (segitiga), tegangan fasa ke fasa sama dengan tegangan fasa (kumparan) yang dapat dituliskan menjadi $V_{F-F}=V_{L}$. Semakin besar nilai frekuensi dan nilai indeks modulasi, maka juga semakin besar nilai tegangan yang dihasilkan dan begitu juga sebaliknya.

Seperti yang ditunjukkan pada Tabel 2, dapat diketahui bahwa nilai arus motor pada tiap fasa menunjukkan hubungan yang linier dengan frekuensi dan indeks modulasi. Selain itu, perubahan nilai arus juga sangat kecil. Hal tersebut, menunjukkan bahwa pada saat motor mulai berjalan (starting) dan setelah motor berjalan (running), tidak terjadi lonjakan arus yang besar. Perubahan nilai arus yang kecil tersebut dapat dilihat seperti yang ditunjukkan oleh grafik nilai arus terhadap nilai frekuensi pada Gambar 13.

Besarnya arus mula (start) motor saat dijalankan secara langsung tanpa menggunakan starter motor, maka arus mulanya akan menjadi 6 kali arus nominalnya. Berdasarkan parameter yang terdapat pada motor, daya keluaran yang dihasilkan motor adalah $0,180 \mathrm{~kW}(0,25 \mathrm{HP})$ dengan faktor daya (cos $\varphi=0,78)$. Pada motor dengan susunan kumparan delta (segitiga), maka tegangan motor adalah $220 \mathrm{~V}$ dan arus motor adalah 0,90 A. Dari data tersebut, besarnya daya masukan motor yaitu:

$$
\begin{aligned}
P_{i n} & =\sqrt{3} V_{L} I_{L} \cos \varphi \\
& =\sqrt{3}(220)(0,90)(0,78) \\
& =0,267 \mathrm{~kW}
\end{aligned}
$$

Maka, arus yang mengalir ke motor adalah:

$$
\begin{aligned}
I_{L} & =\frac{P_{i n}(3 \text { fasa })}{\sqrt{3} V_{L} \cos \varphi} \\
& =\frac{0,267 \mathrm{~kW}}{\sqrt{3}(220)(0,78)}=0,90 \mathrm{~A}
\end{aligned}
$$

Sehingga arus nominal motor pada susunan delta:

$$
I_{n m}=I_{F}=\frac{I_{L}}{\sqrt{3}}=\frac{0,9}{\sqrt{3}}=0,52 \mathrm{~A}
$$

Besarnya arus mula motor saat motor dijalankan secara langsung adalah:

$$
I_{\text {mula }}=6 I_{m}=6(0,52)=3,12 \mathrm{~A}
$$

Dari hasil perhitungan tersebut, dapat diketahui bahwa arus mula motor sebesar 3,12 A tersebut dapat ditekan menjadi $\approx 2,9$ A. Sehingga, penggunaan kontrol skalar dapat menahan lonjakan arus mula motor saat motor mulai berjalan.

Sedangkan bentuk sinyal tegangan keluaran antar fasa ke fasa dan arus pada motor pada salah satu fasa yang dihasilkan, ditunjukkan oleh Gambar 14 . Besarnya harmonisa yang dihasilkan oleh motor dapat diketahui pada spektrum FFT dari sinyal tegangan dan nilai Total Harmonic Distortion (THD) yang ditunjukkan Gambar 15. 


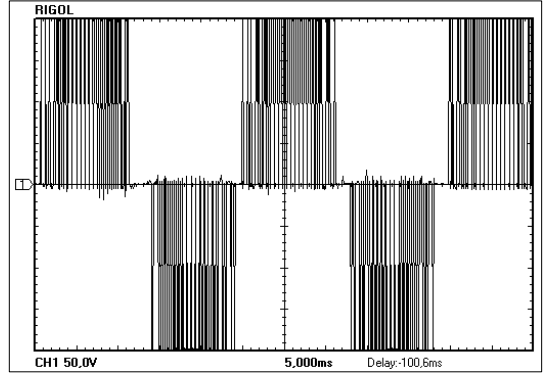

(a)

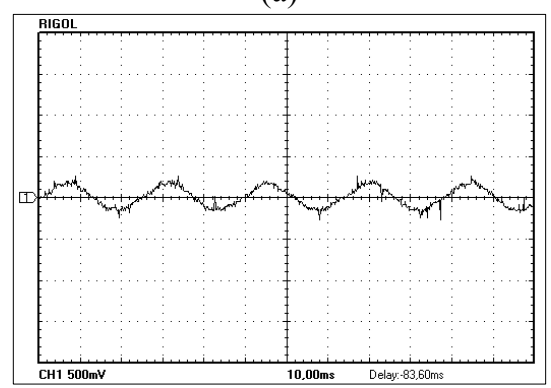

(b)

Gambar 14. Sinyal Keluaran Inverter pada Motor (a) Sinyal Tegangan Fasa- Fasa, dan (b) Sinyal Arus Salah Satu Fasa Motor

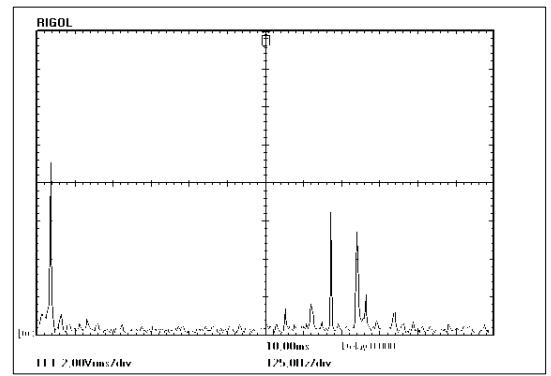

(a)

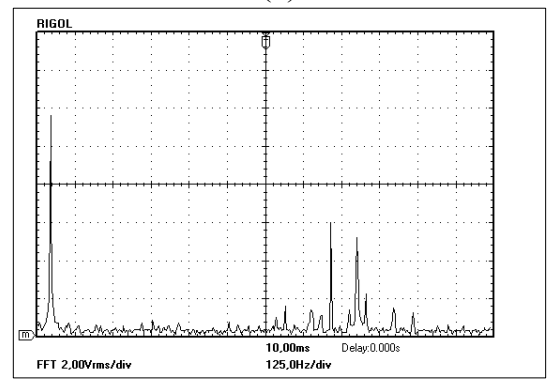

(b)

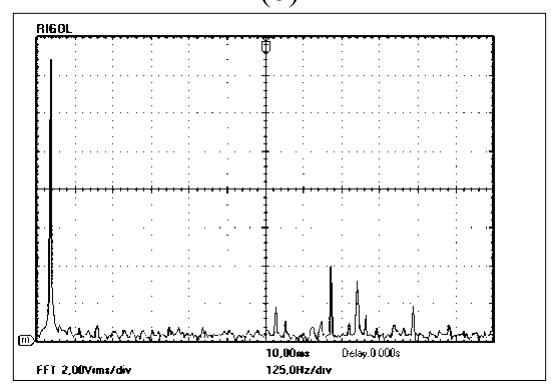

(c)

Gambar 15. Spektrum FFT pada Berbagai Nilai Indeks Modulasi: (a) $M=\mathbf{0 , 6}$, (b) $M=0,8$, dan (c) $M=1,0$
Tabel 3. Nilai Kecepatan Motor Terhadap Nilai Set Point Kecepatan

\begin{tabular}{|c|c|c|}
\hline \multicolumn{2}{|c|}{ Kecepatan (rpm) } & \multirow{2}{*}{$\begin{array}{c}\text { Error } \\
\text { (\%) }\end{array}$} \\
\hline Set Point & Hasil Ukur & 1 \\
\hline 600 & 594 & 0,57 \\
\hline 700 & 704 & 0 \\
\hline 800 & 800 & 2,2 \\
\hline 1000 & 1022 & 2,72 \\
\hline 1250 & 1284 & 0,27 \\
\hline 1500 & 1504 & 4,57 \\
\hline 1750 & 1830 & 5,4 \\
\hline 2000 & 2108 & 0,62 \\
\hline 2250 & 2264 & 2 \\
\hline 2500 & 2450 & 1,935 \\
\hline Rata-rata \% Nilai Error & & \\
\hline
\end{tabular}

Tabel 4. Nilai Frekuensi dan Nilai Indeks Modulasi Terhadap Nilai Set Point Kecepatan

\begin{tabular}{|c|c|c|}
\hline \multirow{2}{*}{$\begin{array}{c}\text { Set Point } \\
\text { Kecepatan }\end{array}$} & \multicolumn{2}{|c|}{ Nilai Keluaran Mikrokontroler } \\
\cline { 2 - 3 } & Frekuensi & Indeks Modulasi \\
\hline $\mathbf{6 0 0}$ & 10.170750 & 0.203415 \\
\hline $\mathbf{7 0 0}$ & 12.026726 & 0.240535 \\
\hline $\mathbf{8 0 0}$ & 13.882703 & 0.277654 \\
\hline $\mathbf{1 0 0 0}$ & 17.594654 & 0.351893 \\
\hline $\mathbf{1 2 5 0}$ & 22.234594 & 0.444692 \\
\hline $\mathbf{1 5 0 0}$ & 26.874535 & 0.537491 \\
\hline $\mathbf{1 7 5 0}$ & 31.514477 & 0.630290 \\
\hline $\mathbf{2 0 0 0}$ & 36.154419 & 0.723088 \\
\hline $\mathbf{2 2 5 0}$ & 40.794357 & 0.815887 \\
\hline $\mathbf{2 5 0 0}$ & 45.434299 & 0.908686 \\
\hline
\end{tabular}

Besarnya THD [5] dapat dihitung menggunakan persamaan:

$$
T H D(\%)=\sqrt{\sum_{h>1}^{h=\infty}\left[\frac{V_{h}}{V_{I}}\right]^{2}} \times 100 \%
$$

dengan $V_{h}=$ tegangan harmonik, $V_{l}=$ tegangan fundamental, dan $h=$ orde harmonik. Perhitungan nilai THD pada masing-masing pengukuran nilai indeks modulasi, adalah:

a. $\quad$ THD pada indeks modulasi $=0,6$ :

$$
\operatorname{THD}(\%)=\sqrt{\left[\frac{6,2}{9}\right]^{2}+\left[\frac{5,2}{9}\right]^{2}} \times 100 \%=89,91 \%
$$

b. THD pada indeks modulasi $=0,8$ :

$$
\operatorname{THD}(\%)=\sqrt{\left[\frac{6}{11,8}\right]^{2}+\left[\frac{5}{11,8}\right]^{2}} \times 100 \%=66,19 \%
$$

c. THD pada indeks modulasi $=1,0$ :

$$
\operatorname{THD}(\%)=\sqrt{\left[\frac{4}{15}\right]^{2}+\left[\frac{3}{15}\right]^{2}} \times 100 \%=33,33 \%
$$

Berdasarkan hasil perhitungan nilai THD, dapat diketahui bahwa semakin besar nilai indeks modulasi, maka semakin kecil nilai THD. Sehingga, semakin kecil nilai tegangan keluaran pada inverter, maka semakin besar harmonisa yang dihasilkan oleh motor. 
Nilai tegangan yang kecil menyebabkan motor tidak dapat bekerja secara optimal. Harmonisa yang dihasilkan menyebabkan pemanasan tambahan pada motor. Nilai THD juga menunjukkan seberapa baik kualitas PWM yang dihasilkan. PWM dengan kualitas baik, dicapai dengan nilai THD yang rendah (mendekati 0\%).

Pengujian sistem dilakukan pada variasi nilai set point kecepatan. Nilai tersebut diubah ke dalam nilai frekuensi dan nilai indeks modulasi untuk diterapkan pada perhitungan algoritma. Nilai kecepatan yang dihasilkan terhadap nilai set point kecepatan, ditunjukkan pada Tabel 3.

Berdasarkan hasil pengukuran kecepatan motor yang ditunjukkan oleh Tabel 3, dapat diketahui bahwa rata-rata nilai error yang dihasilkan dari implementasi sistem kontrol terbuka ini adalah $1,935 \%$. Rata-rata nilai error yang kecil tersebut menunjukkan bahwa sistem kontrol yang diimplementasikan dapat berjalan dan berfungsi dengan baik. Nilai frekuensi dan nilai indeks modulasi yang diberikan pada sistem berdasarkan nilai set point kecepatan, ditunjukkan oleh Tabel 4.

Nilai frekuensi dan nilai indeks modulasi didapatkan dari persamaan yang dihasilkan dari grafik frekuensi dan indeks modulasi terhadap kecepatan, yang ditunjukkan oleh grafik pada Gambar 16 dengan persamaan yang dihasilkan oleh grafik adalah $y=269,4 x+52$. Sehingga untuk mendapatkan nilai frekuensi dapat menggunakan:

$$
x=\frac{y-52}{269,4} \times 5
$$

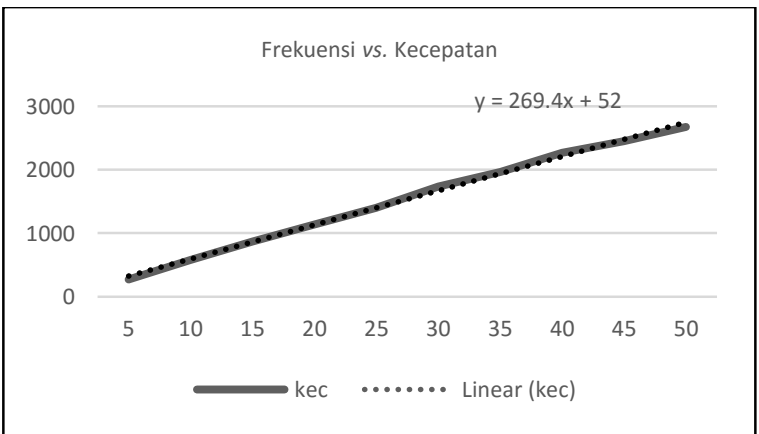

(a)

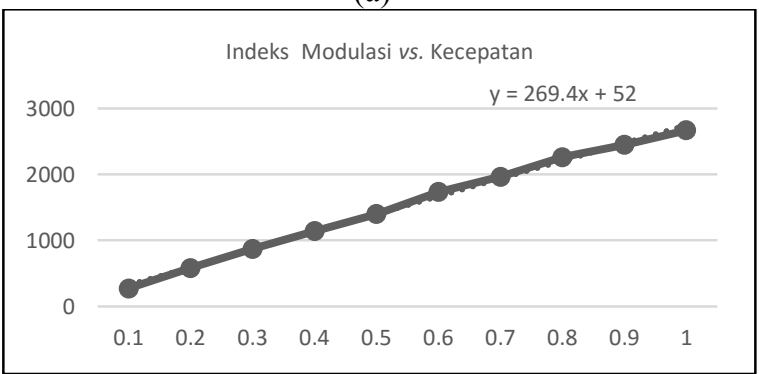

(b)

Gambar 16. (a) Grafik Nilai Frekuensi Terhadap Nilai Kecepatan, (b) Nilai Indeks Modulasi Terhadap Nilai Kecepatan dengan nilai 5 merupakan faktor pengali nilai frekuensi $x$. Dan, untuk menghitung nilai indeks modulasi dapat menggunakan:

$$
x=\frac{y-52}{269,4} \times 0,1
$$

Dengan nilai 0,1 merupakan faktor pengali nilai indeks modulasi $x$. Variabel $y$ merupakan nilai set point kecepatan dan $x$ merupakan nilai yang diinginkan. Perhitungan tersebut ditujukan untuk mendapatkan nilai kecepatan yang sama antara kecepatan aktual motor dengan set point kecepatan tanpa memperhitungkan faktor slip motor. Sehingga, penentuan nilai frekuensi dan indeks modulasi dengan pendekatan pada persamaan tersebut, dapat berfungsi dengan baik, yang ditunjukkan oleh ratarata nilai error yang kecil, yaitu sebesar 1,935\%.

\section{Penutup}

\subsection{Kesimpulan}

Dari hasil pengujian dan analisis yang telah dilakukan, dapat diambil kesimpulan sebagai berikut:

a. Besarnya tegangan keluaran memiliki hubungan yang linier dengan besarnya indeks modulasi. Sedangkan kecepatan motor yang dihasilkan sebanding dengan nilai frekuensi yang diberikan.

b. Kontrol skalar Volt/Hertz mampu menahan lonjakan arus mula motor saat motor mulai dijalankan secara langsung yaitu arus mula motor sebesar 3,12 A dapat ditekan menjadi $\approx 2,9$ A.

c. Nilai rata-rata error pada pengujian kecepatan motor sesuai dengan faktor slip yaitu sebesar $6 \%$. Nilai error pengukuran yang berbeda-beda pada tiap frekuensi, juga dipengaruhi oleh tegangan masukan inverter yang belum maksimal yaitu $303,5 \mathrm{~V}_{\mathrm{dc}} / 214,61 \mathrm{~V}_{\mathrm{ac}}$.

d. Semakin besar nilai indeks modulasi yang diberikan, maka semakin kecil nilai THD. Sehingga, semakin kecil nilai tegangan keluaran pada inverter, maka semakin besar harmonisa yang dihasilkan oleh motor dan motor tidak dapat bekerja optimal.

e. Rata-rata nilai error yang dihasilkan dari implementasi sistem kontrol terbuka adalah 1,935\%. Rata-rata nilai error yang kecil tersebut menunjukkan bahwa sistem kontrol yang diimplementasikan dapat berfungsi dengan baik.

\subsection{Saran}

Untuk pengembangan selanjutnya dan penyempurnaan sistem secara keseluruhan, dapat dilakukan dengan cara:

a. Dirancang kontrol loop tertutup yang disesuaikan dengan aplikasi penggunaannya dan ditambahkan algoritma kontrol lain seperti algoritma genetika dan lainnya.

b. Untuk mempermudah pengguna dalam memodifikasi nilai variabel kontrol, dapat dibuat 
user interface yang dilengkapi dengan tampilan sinyal tegangan dan arus.

c. Modul kontrol dibuat portable dan praktis, sehingga dapat digunakan lebih mudah untuk berbagai bentuk aplikasi penggunaan kontrol motor induksi di dunia industri.

\section{Daftar Pustaka}

[1] Atmel AVR32723, "Sensor Field Oriented Control for Brushless DC Motor with AT32UC3B025", Application Note Rev. 32126A-AVR32-06/09, Atmel Corporation, 2009.

[2] Kumar, K. Vinoth, S. Suresh Kumar, dan Kishore Reddy, "Implementation of Scalar Control Technique in SVPWM Swiched Three-Level Inverter Fed Induction Motor Using DSP Controller", International Journal of Power Electronics and Drive System (IJPEDS), vol. 1, no. 2, ISSN: 2088-8694, pp. 83-93, Desember 2011.

[3] Rashid, Muhammad H., "Power Electronics Circuit, Device, and Applications, 3rd ed.", United States of America: Pearson Prentice Hall, 2004.

[4] Sasi, Devisree dan Jisha Kuruvilla P., "Modelling and Simulation of SVPWM Inverter Fed Permanent Magnet Brushless DC Motor Drive”, International Journal of Advanced Research in Electrical, Electronics and Instrumentation Engineering, vol. 2, issue 5, ISSN (Online): 22788875, pp. 1947-1955, Mei 2013.

[5] Slamet, "Pembangkit Sinyal Pulse Width Modulation (PWM) Tiga Phasa Menggunakan Metode Space Vector Berbasis Microcontroller ATMega 16”, Jurnal Rekayasa Elektrika, vol. 8, no. 2, pp. 62-70, Oktober 2009.

[6] Slamet dan Feri Yusivar, "Perancangan Rangkaian Kontrol Kecepatan Motor Induksi AC Tiga Phasa Meggunakan Metode Space Vector dan Kedali V/f Konstan Berbasis Microcontroller AVR Tipe ATMega16", in Proc. Seminar Ilmiah Nasional Komputer dan Sistem Intelijen (KOMMIT), ISSN: 1411-6286, Auditorium Universitas Gunadarma, Depok, pp.307-312, Agustus 20-21, 2008.

[7] STGIPS10K60A SLLIMM"TM, "Small Low-Loss Intelligent Molded Module) IPM, 3-Phase Inverter - 10A, 600V Short-Circuit Rugged IGBT Datasheet Rev. 9.78”, STMicroelectronics, 2012.

[8] UM0919, "STM32VLDISCOVERY STM32 Value Line Discovery, User Manual Rev. 2”, STMicroelectronics, 2011.

[9] UM0969, "3-Phase Motor Control Demonstration Board Featuring IGBT Intelligent Power Module STGIPS10K60A, User Manual Rev. 2", STMicroelectronics, 2012. 